\title{
A rare complication of
}

\section{inguinal hernia: Small bowel perforation due to falling down}

\section{while walking}

\author{
Serdar Kirmizi* and Bercis Imge Ucar ${ }^{2}$ \\ ${ }^{1}$ Gastroenterology Surgery, Yozgat City Hospital, Yozgat, 66100, Turkey \\ ${ }^{2}$ General Surgery, Yozgat City Hospital, Yozgat, 66100, Turkey
}

Received: 03 February, 2020

Accepted: 26 February, 2020

Published: 27 February, 2020

*Corresponding author: Serdar Kirmizi, MD, Gastroenterology Surgery, Yozgat City Hospital, Yozgat, 66100, Turkey, Tel: 0258 2639311/1598, 05063716212; Fax: 02582619206; E-mail:drserdarkirmizi@hotmail.com

Keywords: Bowel perforation; Blunt abdominal trauma; Inguinal hernia

ORCiD: https://orcid.org/0000-0001-9385-1450 https://www.peertechz.com

Check for updates

\section{Abstract}

Small bowel perforation can occur either spontaneously or due to traumatic causes. Non-traumatic spontaneous small bowel perforation can be caused by various reasons including infectious, inflammatory, congenital, metabolic, vascular or neoplastic origins. Small bowel injury due to blunt trauma is a rare phenomenon compared to other intraperitoneal organ injuries, and frequently appears in high-energy trauma. Yet, even low-energy trauma can cause small bowel perforation in the presence of an inguinal hernia. Several cases of small bowel perforation after abdominal trauma or direct trauma to the hernia site are previously reported, however perforation of the small bowels following a low-energy trauma, such as a fall while marching, is a rare condition. A 65-year-old male admitted to the ER following a sudden onset of severe abdominal pain after 4 hours following a fall while marching. Physical examination revealed a reduced right indirect inguinal hernia. There was diffuse tenderness and defense in the abdomen. The patient was operated due to the acute abdomen after 6hours following a falling down, and primary repair was performed. The patient was discharged on the fifth postoperative day. With this case report, it is aimed to increase the awareness of the surgeons regarding this rare complication.

\section{Introduction}

Small bowel perforation may occur due to traumatic and non-traumatic reasons. Small bowels are the third most common organ injured after a bunt trauma and $10 \%-23 \%$ of these cases may end up with mortality [1]. Inguinal hernia is a risk factor for small bowel perforation following a blunt trauma [2]. A few cases of small bowel perforation after abdominal trauma or direct trauma to the hernia site are previously reported $[3,4]$. However perforation of the small bowels following a mild trauma, such as a fall while marching, is a rare condition. In the present case, isolated small bowel perforation is detected and primary repair is performed during an exploratory laparotomy of the patient with acute abdomen.

\section{Case}

A 65-year-old male admitted to the ER following a sudden onset of a severe abdominal pain after tripping over a stone while marching. On initial physical examination, level of consciousness and vital signs were within normal range. His complete blood count showed leukocytosis $\left(13,4 \times 10^{3} \mathrm{~mL}\right)$ and his biochemical routine tests were as follows: amylase, $122 \mathrm{~m} / \mathrm{l}$; lipase, 109m/L; glucose: $185 \mathrm{mg} / \mathrm{dL}$; creatinin, $1,18 \mathrm{mg} /$ dL. Physical examination revealed a reduced right indirect inguinal hernia and four quadrant tenderness and defense. No sign of acute trauma was found on the abdominal skin. CT scan showed free intraperitoneal air and fluid (Figure 1). Informed consent was obtained and patient gone under surgery after 6 hours following the fall. He had a medical history of type 2 diabetes mellitus for a long time and right inguinal hernia for a year (Figure 2). There was no prior history of surgery with no prescribed medicine intake (except oral antidiabetics). On exploratory lapartomy, a $1 \mathrm{~cm}$ wide small bowel perforation at the antimesenteric border which is located $200 \mathrm{~cm}$ distal to Treitz ligament (Figure 3). Primary repair was performed. No incarceration sign, diverticulitis, tumoural or vascular lesion leading to bowel perforation was found. The hernia defect was repaired intraabdominally. The patient was discharged on the fifth postoperative day.

\section{Discussion}

Three-quarter of the abdominal wall hernias are inguinal 


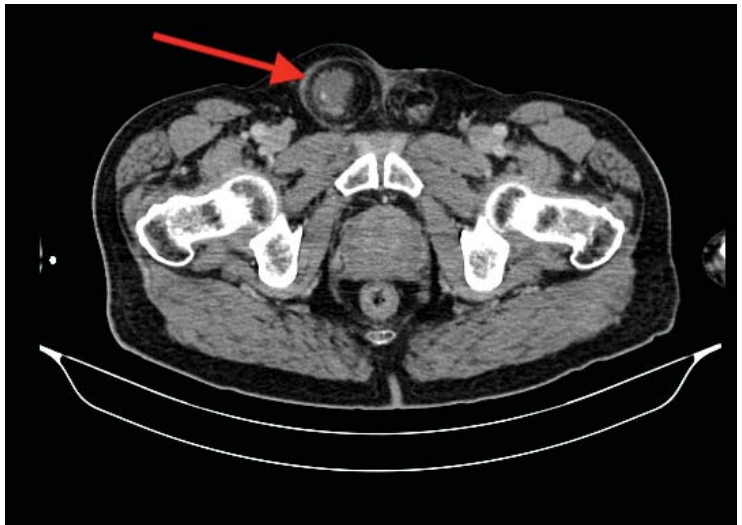

Figure 1: Axial abdomen CT scan showing riht inguinal hernia.

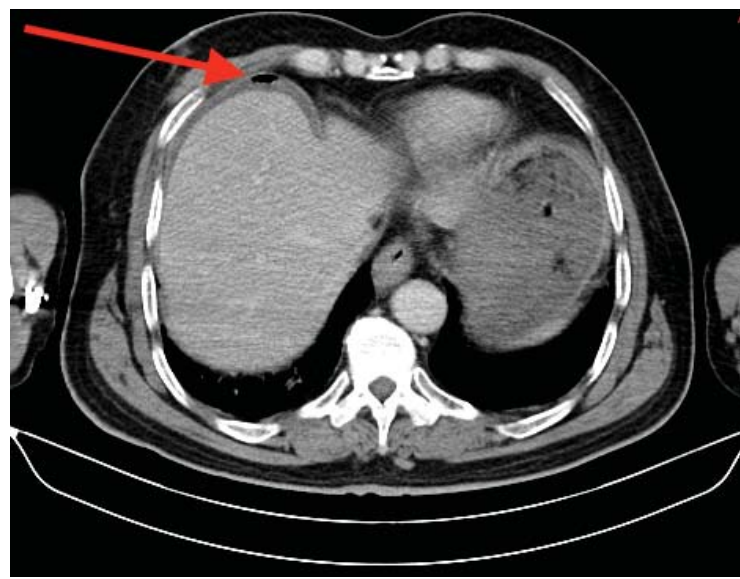

Figure 2: Scan of abdomen shows free intraperitoneal air and collection (arrow) suggesting intestinal perforation.

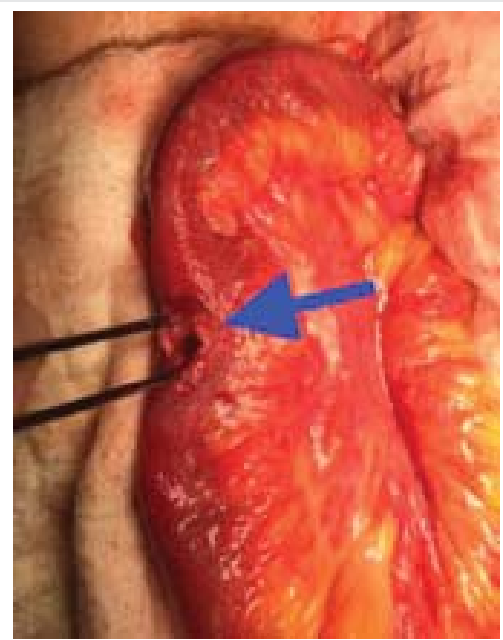

Figure 3: The view of intraoperative antimezenteric perforation.

hernias and male-to-female ratio of the disease is 8:1 [5]. The most severe complications of inguinal hernia are incarceration and strangulation. Traumatic small bowel perforation is a rare complication of inguinal hernia and $70 \%$ of the perforations occur in the jejuno-ileal intestinal segment [6]. Intestinal perforation may occur both after an impact to the abdominal wall and directly to the hernia site. Vyas, et al., reported that the rate of intestinal perforation after blunt trauma is higher in patients over 40years of age with hernia (inguinal, femoral, perineal and incisional) in comparison with the healthy subjects at the same age range [7].

There are several assumptions about the mechanism of intestinal perforation after blunt abdominal trauma in patients with inguinal hernia. Although, healthy abdominal wall structures protect the intestines from the increased intraabdominal pressure caused by blunt trauma under normal conditions, a soft spot for perforation occurs because of the hernia at the level of orifice as the abdominal wall structures can not provide enough support to the intestines. Another suggested mechanism is associated with the sudden intraluminal pressure increase which leads to perforation due to obstruction of the afferent and efferent intestinal segments in the hernial sac. This sudden increase of the pressure can go up to $300 \mathrm{mmHg}$ and previous studies showed that increase in the intraluminal pressure up to $150 \mathrm{mmHg}-260 \mathrm{mmHg}$ can cause perforation [8]. No incarcerated hernia may be detected, as the herniated intestinal segment can reduce spontaneously after the intraabdominal pressure decreases post-traumatically. Both mechanisms can cause small bowel perforation at the antimesenteric border. Seromuscular lacerations, hematoma and segmental ischemic lesions are typical after a high-energy trauma like traffic accident, fall from height which constitutes $70 \%-90 \%$ of the causes of the blunt abdominal traumas [9]. Isolated small bowel or mesentery of the small bowel injuries are seen in only $2.9 \%$ of these traumas as they are usually accompanied by solid organ injuries (like liver or spleen) [10].

Non-traumatic spontaneous small bowel perforation can be caused by various reasons including infectious, inflammatory, congenital, metabolic, vascular or neoplastic origins [11]. Though, non-operative treatment of small bowel injuries with close follow-ups is an option, surgical treatment is inevitable if the patient is hemodynamically unstable or there are findings of pneumoperitoneum or peritonitis.

The presence of a hernia is a risk factor for small bowel perforation, even after a mild trauma. It should be kept in mind that untreated inguinal hernias may cause unusual complications.

\section{References}

1. Hughes TMD, Elton C, Hitos K, Perez JV, Mcdougall PA (2002) Intra abdominal gastrointestinal tract_injuries following_blunt trauma the experience of an Australian trauma centre. Injury 33: 617-626. Link: http://bit.ly/3920WfG

2. Cartanese C, Guastadisegno C, Magli M, Franco F, Frattini P, et al. (2019) Intestinal perforation secondary to blunt abdominal trauma in pre-existing inguinal hernia. G Chir 40: 230-233. Link: http://bit.ly/37ZMT8Y

3. Liu D, Zhu L, Wang M (2017) Trauma to an inguinal hernia resulting in bowe rupture: A case report and literature review. Int J Surg Case Rep 41: 495-497. Link: http://bit.ly/2vh1fob

4. Neuhaus V, Turina M, Colombo G, Soklic P, Simmen HP (2009) Intestinal perforation following blunt abdominal trauma in patients with pre-existing inguinal hernia. Chirurg 80: 231-237. Link: http://bit.ly/3cjBYKS

5. Köckerling F, Simons MP (2018) Current Concepts of Inguinal Hernia Repair Visc Med 34: 145-150. Link: http://bit.ly/3a4ek2N 
6. Shahin Y, Sahota G, Hotouras A, Agarwal A, Tierney G (2012) Small bowel perforation due to blunt trauma to an inguinal hernia: a case report and literature review. Hernia 16: 349-350. Link: http://bit.ly/2VzoswP

7. Payson BA, Mage S (1962) Role of inguinal hernia in acute perforation of the small intestine secondary to blunt abdominal trauma. Ann Surg 156: 944-950. Link: http://bit.ly/32rBhdT

8. Alsayali DMM, Atkin C, Winnett J, Rahim R, Niggemeyer LE, et al. (2009) Management of blunt bowel and mesenteric injuries: experience at the Alfred hospital. Eur J Trauma Emerg Surg 35: 482-488. Link: http://bit.ly/3cdJI10
9. Bekker W, Kong VY, Laing GL, Bruce JL, Manchev V, et al. (2018) The spectrum and outcome of blunt trauma related enteric hollow visceral injury. Ann R Coll Surg Engl 100: 290-294. Link: http://bit.ly/2HTeONr

10. Freeman HJ (2014) Spontaneous free perforation of the small intestine in adults. World J Gastroenterol 20: 9990-9997. Link: http://bit.ly/3ahDeMP

11. Campıon EM, Burlew CC (1977) Small Bowel Perforation. In: Brown CVR, Inaba K, Martin MJ, Salim A (2019) Emergency General Surgery. Springer Cham 21321. Mathematical encyclopedia. Soviet Encyclopedia 1.
Discover a bigger Impact and Visibility of your article publication with

Peertechz Publications

\section{Highlights}

* Signatory publisher of ORCID

* Signatory Publisher of DORA (San Francisco Declaration on Research Assessment)

* Articles archived in worlds' renowned service providers such as Portico, CNKI, AGRIS, TDNet, Base (Bielefeld University Library), CrossRef, Scilit, J-Gate etc.

* Journals indexed in ICMJE, SHERPA/ROMEO, Google Scholar etc.

- OAI-PMH (Open Archives Initiative Protocol for Metadata Harvesting)

* Dedicated Editorial Board for every journal

- Accurate and rapid peer-review process

* Increased citations of published articles through promotions

* Reduced timeline for article publication

Submit your articles and experience a new surge in publication services

(https://www.peertechz.com/submission).

Peertechz journals wishes everlasting success in your every endeavours.

Copyright: @ 2020 Kirmizi S, et al. This is an open-access article distributed under the terms of the Creative Commons Attribution License, which permits unrestricted use, distribution, and reproduction in any medium, provided the original author and source are credited. 